\title{
Fabrication and Magnetic Properties of CoNiAl Ferromagnetic Shape memory Alloy thin films
}

\author{
B.Rajini Kanth ${ }^{1, a}$, D.Bhattacharjya ${ }^{2}$ and P.K. Mukhopadhyay ${ }^{1, b}$ \\ ${ }^{1}$ LCMP, S.N.Bose National Center for Basic Sciences, Salt Lake, Kolkata, India \\ ${ }^{2}$ Faculty of Technology and Engineering, M.S.University of Baroda, Baroda \\ arajani@bose.res.in, ${ }^{b}$ pkm@bose.res.in
}

\begin{abstract}
Keywords: CoNiAl Ferromagnetic Shape Memory Alloys, Thin films, D.C Sputtering, Magnetic properties
\end{abstract}

\begin{abstract}
Study o Ferromagnetic shape memory alloys (FSMAs) is an interesting topic of present day research because of their large magnetic field induced shape recovery. They are important materials for the development of sensors and actuator based applications. Attempt for miniaturization of these actuators and sensors have led to the study of thin films. Bulk CoNiAl alloys are promising FSMAs because of their higher ductility and large range of control over the magnetic and structural transformation temperatures. To investigate the physical properties in thin film form we fabricated CoNiAl alloy films by D.C. sputtering method on glass substrates (kept at room temperature) under various conditions. They were annealed in vacuum at $500{ }^{0} \mathrm{C}$ for $1 \mathrm{~h}$. The samples were characterized by X-ray diffraction, scanning electron microscopy, energy dispersive $\mathrm{X}$-ray analysis and ellipsometry. Thickness of the films was found to be lying between 70 and 272 $\mathrm{nm}$. Fine grained microstructure was found for all the deposited films. The transformation temperatures of the samples were taken from the resistivity measurement done between 80 and 350 $\mathrm{K}$. Magnetization measurements were also done between 80 and $400 \mathrm{~K}$ by using a vibrating sample magnetometer, but the Curie temperatures of the present films were not found to be below $400 \mathrm{~K}$ and magnetoelastic couplings were found to be rather weak.
\end{abstract}

\section{Introduction}

Ferromagnetic shape memory alloy (FSMA) thin films are promising candidates for sensors and actuators applications. FSMAs have higher magnetostrain and sharper response to the external stimulus compared to ordinary shape memory materials [1, 2]. Bulk CoNiAl alloys are useful FSMA materials because of their higher ductility compared to archetypal FSMA, the $\mathrm{Ni}_{2} \mathrm{MnGa}$, and because of large range of magnetic and structural transformation temperatures [3, 4].

Keeping in mind the bulk properties of CoNiAl alloy, we wanted to know how these will be in thin film form for its practical applications. Since it is very difficult to keep proper chemical composition control in the final CoNiAl thin films, we have chosen the present study to optimise the composition and fabrication parameters. We have made these films by D.C. sputtering and a detailed study of physical properties of such films were done. We have chosen the D.C. sputtering because of its simplicity, cost effectiveness and universality for fabrication of alloy thin films.

\section{Experimental}

99.9\% pure powders of $\mathrm{Co}, \mathrm{Ni}$ and $\mathrm{Al}$ metals were taken in proper proportion, ground for several hours and pressed into a pellet of $2.5 \mathrm{~cm}$ diameter and $2 \mathrm{~mm}$ thickness. It was then attached to the target holder in the sputtering chamber. Here, two targets were used, target-I was Al rich $\left(\mathrm{Co}_{34} \mathrm{Ni}_{32} \mathrm{Al}_{34}\right)$ and with this, first three samples (Sample nos. 1 to 3) were made. Target-II was Ni rich $\left(\mathrm{Co}_{34} \mathrm{Ni}_{38} \mathrm{Al}_{28}\right)$ with this the other three samples (Sample nos. 4 to 6) were made. The sputtering unit used was a modified version of Hind Highvac Coating unit. In this arrangement, the target was placed on top and connected to the high voltage electrode by means of a $\mathrm{Cu}$ connector, and the substrate was kept down at a distance of $2.5 \mathrm{~cm}$ from the target that was kept at room temperature. We used glass substrates here. Ar gas was used in the chamber for protection as well as for 
sputtering of the alloy, at a working pressure of 0.2 mbar inside the chamber. Thin films were fabricated with supply powers of $52.5 \mathrm{~W}, 87.5 \mathrm{~W}$ and $122.5 \mathrm{~W}$ for periods of 60 min and 90 min. As the target and substrate were kept close, the films were deposited with good uniformity throughout the circular area of the target dimension on the substrate. The samples were then annealed at $500{ }^{0} \mathrm{C}$ and slowly cooled to room temperature. The as-deposited and annealed samples were characterized by x-ray diffraction (XRD), scanning electron microscopy (SEM), energy dispersive $\mathrm{x}$-ray analysis (EDAX) and ellipsometry. A.C. resistivity measurements were done by using four-probe method in the temperature range from 80 to $350 \mathrm{~K}$ at $111 \mathrm{~Hz}, \mathrm{M}-\mathrm{H}$ measurements were done by using a Vibrating Sample Magnetometer (VSM) at different temperatures from $80 \mathrm{~K}$ to $400 \mathrm{~K}$ and in fields up to $16 \mathrm{kOe}$. Magnetization measurements were also done at a field of 500 Oe between $80 \mathrm{~K}$ and $400 \mathrm{~K}$ while cooling and heating. In both cases, the magnetic field was applied perpendicular to the plane of the film surface.

\section{Results and Discussion}

Figures 1(a), (b) and (c), (d) respectively show the XRD patterns of the as-deposited and annealed sample nos. 3 and 4 . We note that due to the thinness of films the data were somewhat noisy. XRD patterns indicate that the present $\mathrm{CoNiAl}$ alloy thin films have been formed with varying amounts of the two phases, $\beta$ and $\gamma$. It is reported that the $\beta$ phase has a bcc and the $\gamma$ phase has a fcc structures at room temperature [5]. It was also found that the XRD patterns of the annealed samples were narrower with higher crystallinity and a few more peaks were present as compared to those from the as-deposited samples. However they are still less in number as compared to those of bulk CoNiAl samples. The peaks were marked with their corresponding phases in the XRD plots. Finally, we also note the absence of less intense peaks for the $\beta$ and $\gamma$ phases in the XRD. It may mean that there are some textures in the samples but the data being somewhat noisy precludes us from commenting.

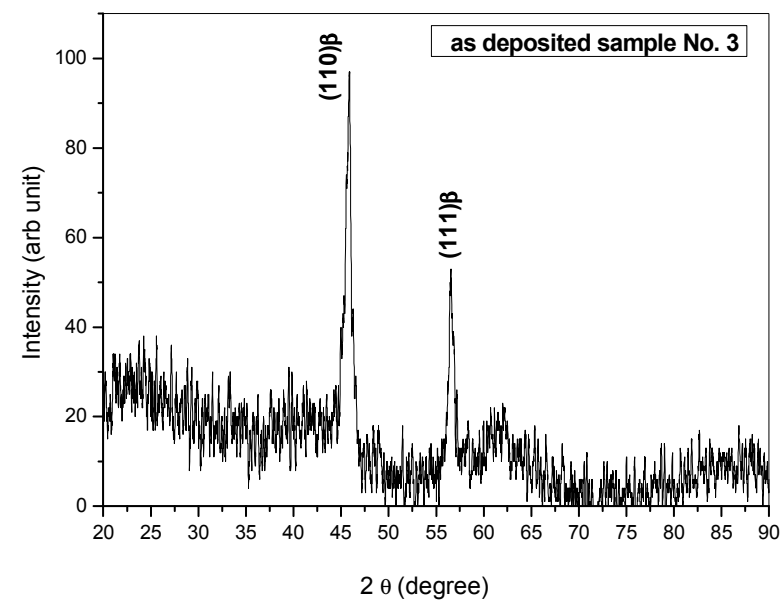

(a)

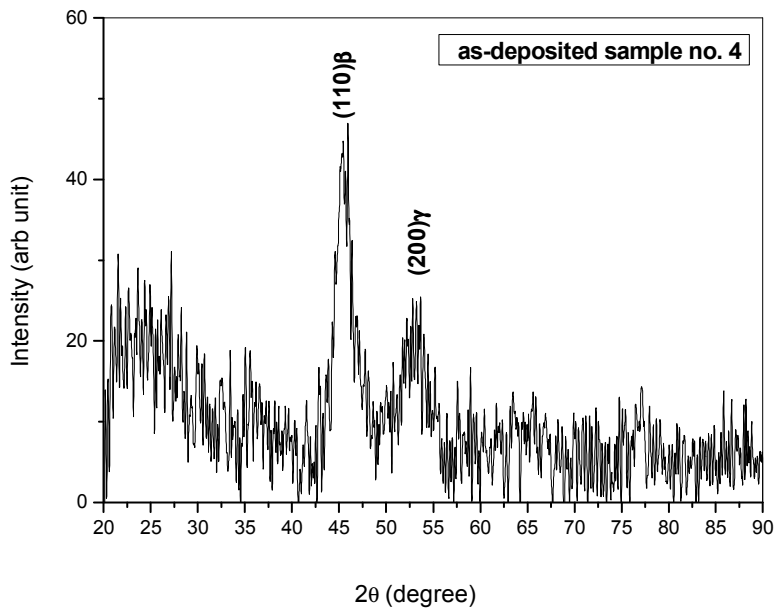

(b)

Fig. 1: (a) and (b) XRD pattern of as-deposited sample nos. 3 and 4 


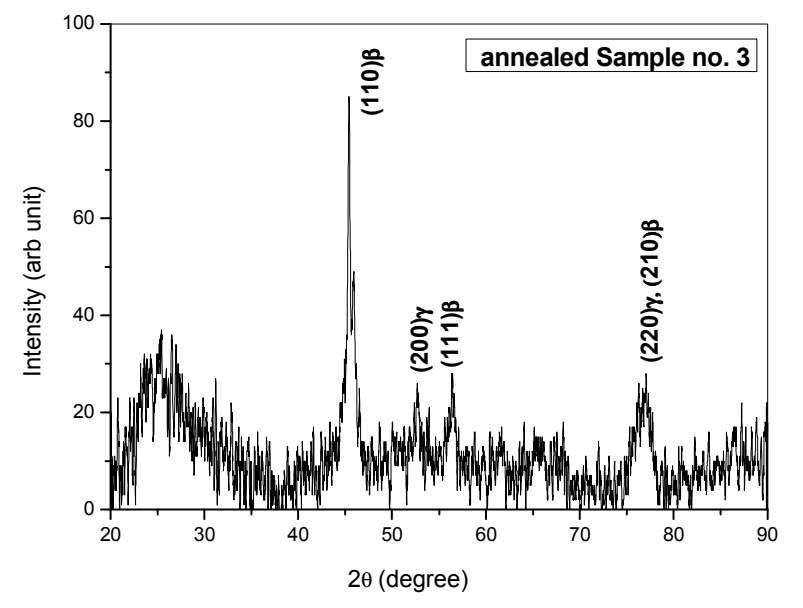

(c)

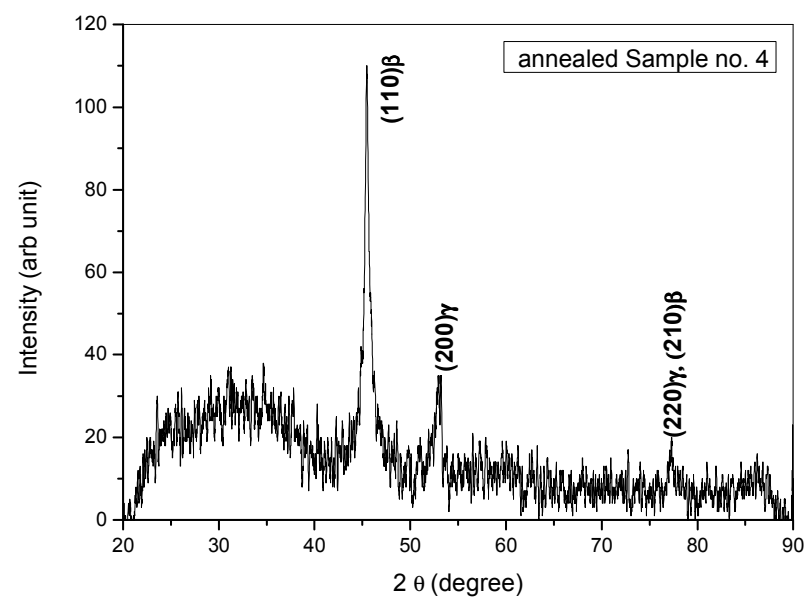

(d)

Fig. 1: (c) and (d) XRD pattern of annealed sample nos. 3 and 4

Figures 2(a), (b) and (c), (d) show the SEM images of the as-deposited and annealed sample nos. 3 and 4 CoNiAl alloy thin-films respectively. From the figures we find that the samples possesses fine grained microstructure and compared to as-deposited films, the annealed samples have slightly larger grain size. As compared to the sample no. 3, sample no. 4 has finer and more uniform grains. The preparation data of as-deposited and annealed films are given in Table 1.
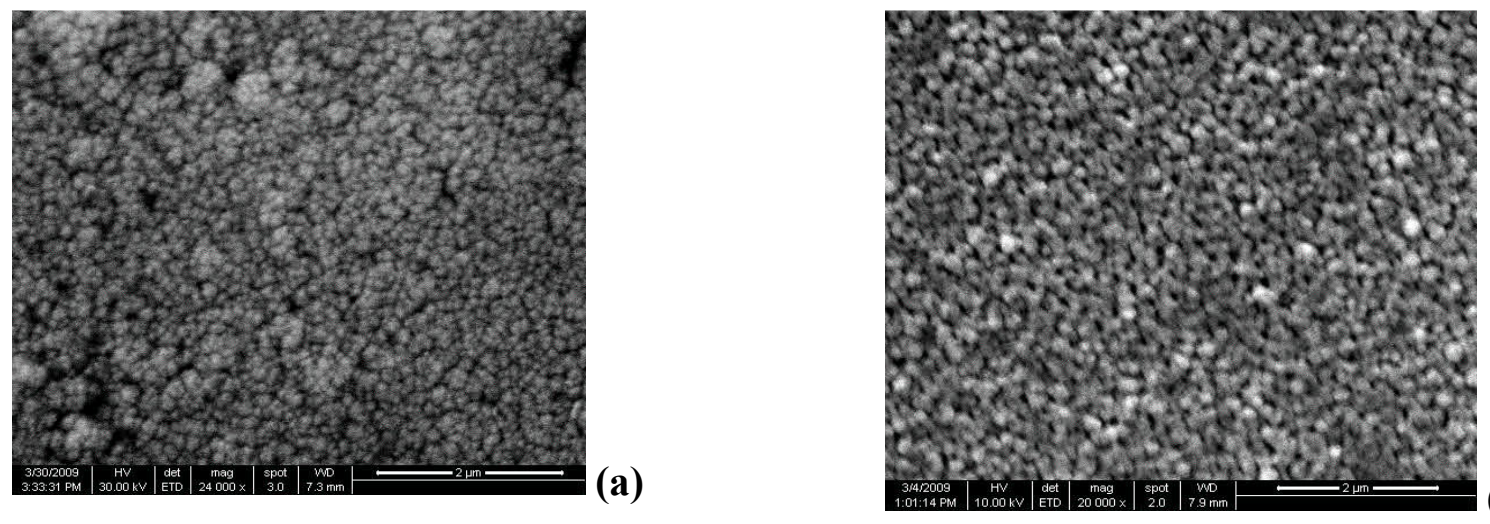

(b)
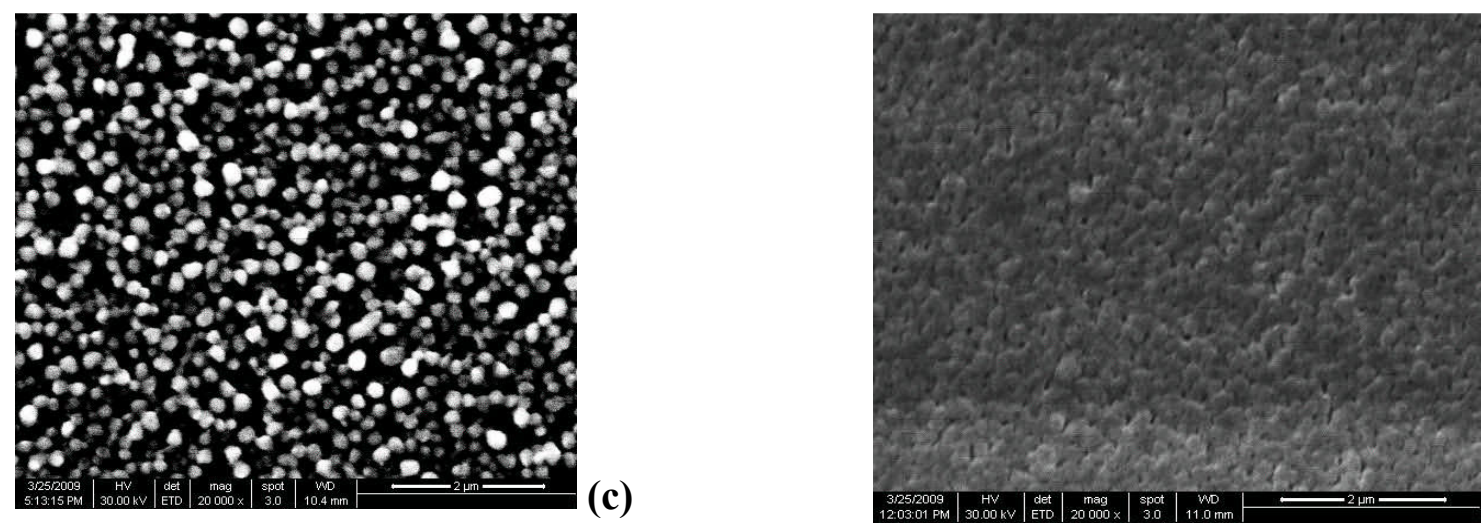

(d)

Fig. 2: (a) and (b) SEM photographs of as-deposited sample nos. 3 and 4. (c) and (d) SEM photographs of annealed sample nos. 3 and 4 
Compositions of the present samples were determined from the EDAX measurements done at five different places and the average values are presented in Table 1. Ellipsometric data showed that the present samples have thickness between $70 \mathrm{~nm}$ and $272 \mathrm{~nm}$ and that the thickness of each sample increased a bit after annealing. From table 1, it was found that the sample nos. 3 and 4 have a uniform microstructure with fine grains, and higher thickness as compared to other samples. Besides, it was found that these samples have least tendency of peeling off the substrates. Hence, they were used for further study of electrical transport and magnetic property.

Table 1. Room temperature physical parameters of as-deposited and annealed Co-Ni-Al thin films.

\begin{tabular}{|c|c|c|c|c|c|c|c|}
\hline \multirow{2}{*}{$\begin{array}{c}\text { Sample } \\
\text { No }\end{array}$} & \multirow{2}{*}{$\begin{array}{l}\text { Power } \\
\text { used } \\
\text { (Watt) }\end{array}$} & \multirow{2}{*}{$\begin{array}{l}\text { Time of } \\
\text { Sputtering } \\
\text { (min) }\end{array}$} & \multirow{2}{*}{$\begin{array}{l}\text { Thickness } \\
\text { (nm) }\end{array}$} & \multicolumn{3}{|c|}{ Atomic $(\%)$} & \multirow{2}{*}{$\begin{array}{l}\text { Grain Size } \\
\quad(\mathrm{nm})\end{array}$} \\
\hline & & & & $\mathrm{Co}$ & $\mathrm{Ni}$ & $\mathrm{Al}$ & \\
\hline $\begin{array}{l}1 \\
\text { Annealed } 1\end{array}$ & 52.5 & 60 & $\begin{array}{l}70 \\
76\end{array}$ & $\begin{array}{l}12.83 \\
14.12\end{array}$ & $\begin{array}{l}30.91 \\
23.07\end{array}$ & $\begin{array}{l}56.27 \\
62.77\end{array}$ & - \\
\hline $\begin{array}{l}2 \\
\text { Annealed } 2\end{array}$ & 122.5 & 60 & $\begin{array}{l}145 \\
176\end{array}$ & $\begin{array}{l}15.50 \\
15.11\end{array}$ & $\begin{array}{l}20.56 \\
20.52\end{array}$ & $\begin{array}{l}63.94 \\
64.37\end{array}$ & $\begin{array}{l}58 \\
88\end{array}$ \\
\hline $\begin{array}{l}3 \\
\text { Annealed } 3\end{array}$ & 122.5 & 90 & $\begin{array}{l}251 \\
272\end{array}$ & $\begin{array}{l}21.35 \\
19.68\end{array}$ & $\begin{array}{l}24.67 \\
22.44\end{array}$ & $\begin{array}{l}53.98 \\
57.88\end{array}$ & $\begin{array}{l}140 \\
157\end{array}$ \\
\hline $\begin{array}{l}4 \\
\text { Annealed } 4\end{array}$ & 122.5 & 90 & $\begin{array}{l}214 \\
219\end{array}$ & $\begin{array}{l}22.33 \\
22.68\end{array}$ & $\begin{array}{l}36.71 \\
36.23\end{array}$ & $\begin{array}{l}40.96 \\
41.09\end{array}$ & $\begin{array}{l}123 \\
133\end{array}$ \\
\hline $\begin{array}{l}5 \\
\text { Annealed } 5\end{array}$ & 87.5 & 60 & $\begin{array}{l}107 \\
115\end{array}$ & $\begin{array}{l}13.30 \\
11.30\end{array}$ & $\begin{array}{l}26.55 \\
21.50\end{array}$ & $\begin{array}{l}60.15 \\
67.21\end{array}$ & - \\
\hline $\begin{array}{l}6 \\
\text { Annealed } 6\end{array}$ & 87.5 & 90 & $\begin{array}{l}122 \\
149\end{array}$ & $\begin{array}{l}13.55 \\
12.79\end{array}$ & $\begin{array}{l}18.12 \\
18.73\end{array}$ & $\begin{array}{l}67.53 \\
68.48\end{array}$ & $\begin{array}{l}60 \\
78\end{array}$ \\
\hline
\end{tabular}

To determine the transformation temperatures, we have carried out resistivity measurements on annealed sample nos. 3 and 4. From Figure 3(a), it may be seen that there was a slope change at about $220 \mathrm{~K}$ and another at $150 \mathrm{~K}$. We may assign these to structural changes in the system, labeled as $\mathrm{T}_{\mathrm{Ms}}$ and $\mathrm{T}_{\mathrm{Mf}}$ respectively, i.e. the transition started initially at $\mathrm{T}_{\mathrm{Ms}}$ and finished at $\mathrm{T}_{\mathrm{Mf}}$ on cooling. On heating the phase transition starts at $150 \mathrm{~K}$ where the line deviated from the cooling curve and it again merged at around $220 \mathrm{~K}$. Attributing these to structural transitions, we label them similarly as austenite start, $\mathrm{T}_{\mathrm{As}}$ and austenite finish, $\mathrm{T}_{\mathrm{Af}}$. The change of resistivity at martensite/austenite phase transition is expected due to variation in the electronic density of states at the Fermi level [6] during the structural modifications. But the resistivity hysteresis curve is so fine in this case that it is not possible to unambiguously distinguish between $\mathrm{T}_{\mathrm{Mf}}$ and $\mathrm{T}_{\mathrm{As}}$, and $\mathrm{T}_{\mathrm{Af}}$ and $\mathrm{T}_{\mathrm{Ms}}$. Similarly, for the sample no. 4 corresponding transition temperatures are derived from the slope changes in resistivity. For the sample no.4, martensite starts around $295 \mathrm{~K}$ and finishes at around $120 \mathrm{~K}$ and austenite starts around $195 \mathrm{~K}$ and finishes around $337 \mathrm{~K}$. These transformation temperatures were marked in the resistivity plots. The $\mathrm{T}_{\mathrm{As}}$ in this case was derived from slope changes from high temperature and from low temperature sides, the extrapolated lines are shown in the figure also. Similarly, $\mathrm{T}_{\mathrm{Ms}}$ was assumed to be where there was a marked deviation from the extrapolation from high temperature side. There are also some fine structures visible in both the heating and cooling curves, we believe that these were due to intermartensites. However, the changes are too small here to make definitive temperature assignments, we presume that the thinness of the films is the cause of such weak electron-phonon coupling. 


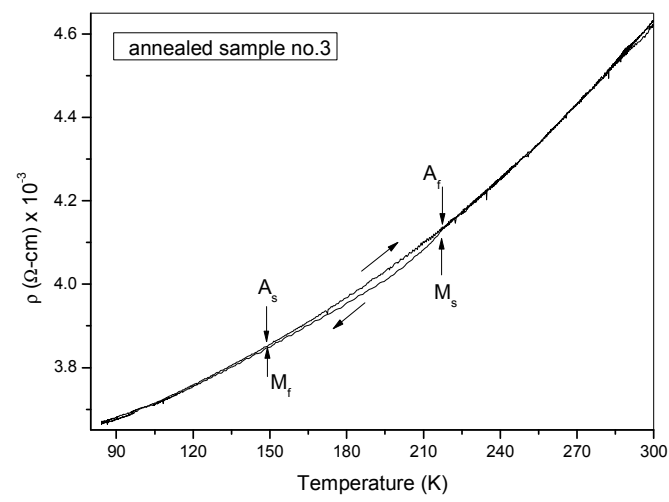

(a)

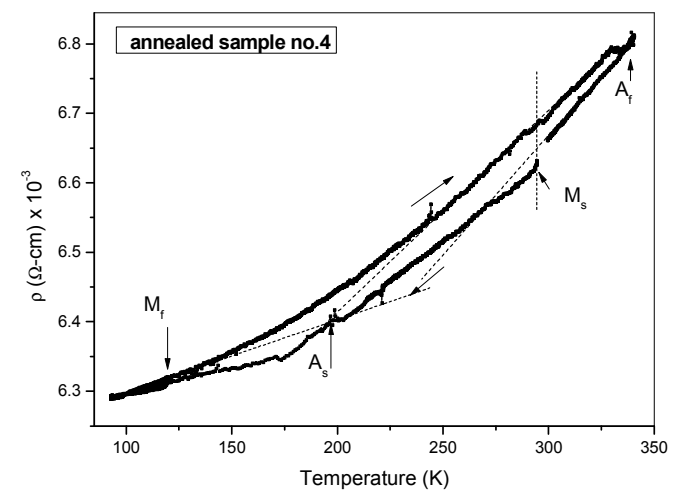

(b)

Fig. 3: (a) and (b) A.C. resistivity plots of annealed sample nos. 3 and 4 recorded while cooling and heating (dotted lines are guides for the eye).

Figures 4(a) and (b) show the magnetic hysteresis behaviour of the annealed samples up to 16 $\mathrm{kOe}$ field at different temperatures. While we have done measurements at 80, 150, 200, 250, 300, 350 and $400 \mathrm{~K}$, we are presenting data for only three well-chosen sets in each graph for sake of clarity. The trend is better visible this way. The behaviour was similar to a soft ferromagnet, and the coercivity was found to increase slightly with lowering the temperature. It was also to be noted that below $200 \mathrm{~K}$, we could not achieve saturation in these cases up to the maximum available field. In case of the second sample, the increase in magnetization was evidently due to higher number of magnetic ions, but even then the sharp increase of high field magnetization below $300 \mathrm{~K}$ is striking.

Temperature variation of magnetization measurements were done for both the annealed samples no. 3 and 4 at 500 Oe field both in cooling and heating cycles. In both cases the samples were ferromagnetic till $400 \mathrm{~K}$ and as expected from the previous figure, sample no. 3 had less magnetization than the other sample. However, in case of the first sample, we found no discernable changes in magnetizations during any transition whereas the sample no. 4 showed small but distinctive features near two structural transformations. The data are plotted in fig. 5. We find that the $\mathrm{T}_{\mathrm{Af}}$ and $\mathrm{T}_{\mathrm{Ms}}$ happen to lie in about the middle of the troughs. Still the changes are too small to be

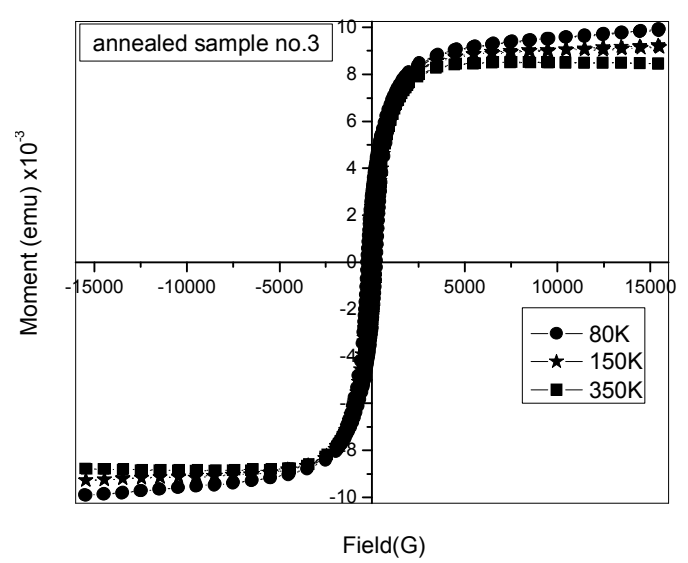

(a)

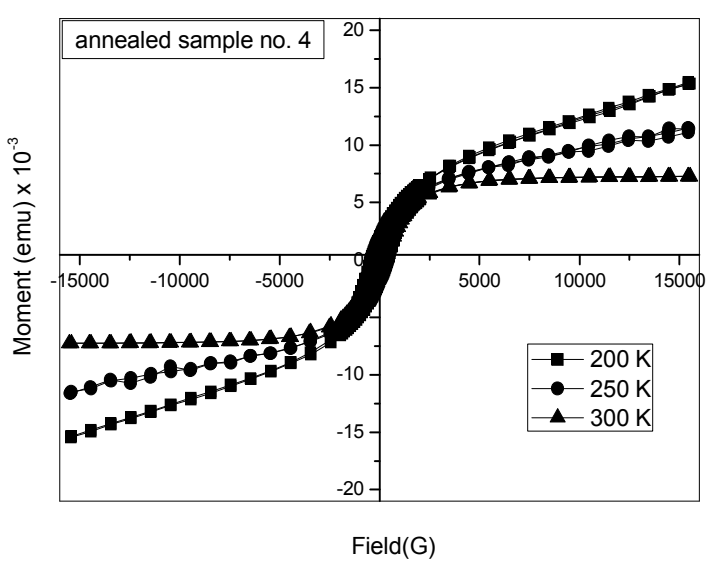

(b)

Fig. 4: (a) and (b) M-H plots of annealed sample nos. 3 and 4 at different temperatures, field applied perpendicular to the plane of the films. 


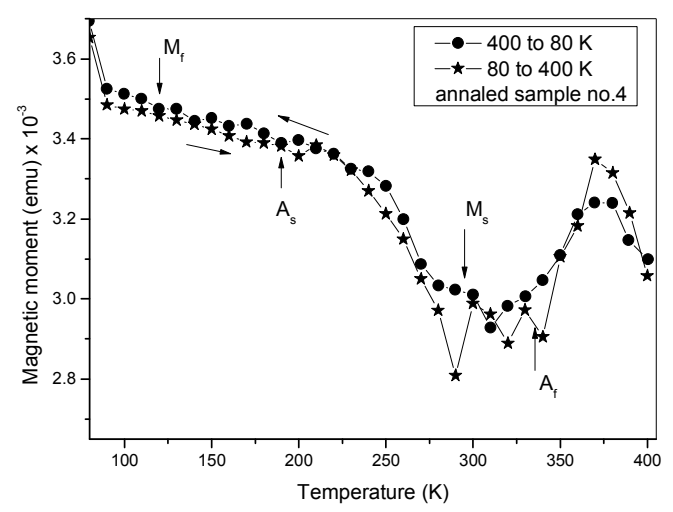

Fig. 5: M-T plot of annealed sample no. 4 during cooling and heating ( $80 \mathrm{~K}$ to $400 \mathrm{~K})$

confidently associated with the structural parameters. This is unlike the behaviour generally observed in the bulk and is puzzling. Therefore, we believe that the signatures of the structural transitions in the M-T behaviour are not very prominent in the films. More in depth study in this line is called for.

\section{Conclusions}

We have fabricated CoNiAl thin-films by D.C. sputtering method on glass substrates. The samples show a two phase structure at room temperature. Of all samples, sample no. 3 with the composition $\mathrm{Co}_{21} \mathrm{Ni}_{25} \mathrm{Al}_{54}$ and sample no. 4 with the composition $\mathrm{Co}_{22} \mathrm{Ni}_{37} \mathrm{Al}_{41}$ were found to have good physical properties and less $\mathrm{Al}$ content as compared with other alloys and their magnetic and transport properties were also studied in detail.

\section{Acknowledgements}

We acknowledge Dr. D. Das and P.V. Rajesh, IUC, DAE, Kolkata chapter for extending us the experimental facilities. One of the authors, BRK acknowledges financial support from the Department of Science and Technology, India, vide project grant no.: SR/S2/CMP-24/2006.

\section{References}

[1] I. Suorsa, J. Tellinen, E. Paguonis, I. Aaltio and K. Ullakko: Applications of Magnetic Shape memory actuators, Proc. Actuator (2002), p. 158.

[2] T. Kakeshita, T. Takeuchi, T. Fukuda, T. Saburi, R. Oshima and S. Muto: Appl. Phys. Lett. Vol. 77 (2000), p. 1502

[3] K. Oikawa, L. Wulff, and T. Iijima, F. Gejima, T. Ohmori, A. Fujita, K. Fukamichi, R. Kainuma and K. Ishida: Appl. Phys. Lett. Vol.79 (2001), p. 3290.

[4] K. Oikawa, T. Ota, F. Gejima, T Omori, R. Kainuma and K. Ishida: Mater. Trans. Vol. 42 (2001), p. 2472.

[5] Y. Tanaka, K. Oikawa, Y. Sutou, T Omori, R. Kainuma and K. Ishida: Mater. Sci. Eng. A Struct. 438-440 (2006), p. 1054.

[6] O. Heczko, S.Fähler, T.M. Vasilchikova, T.N. Voloshok, K.V. Klimov, Yu. I. Chumlyakov and A.N. Vasiliev: Phys. Rev. B Vol.77 (2008), p. 174402 